\section{Estimating the Prevalence of Attention Deficit Hyperactivity Disorder in Castile-La Mancha, Spain (1992-2020)}

\section{Abstract}

Background: Attention Deficit and Hyperactivity Disorder (ADHD) is one of the most common behavioral disorders of childhood, its prevalence in Spain is estimated at $6.8 \%$. Studies have shown an increase in the use of ADHA medications. The aim of this study was to learn the pattern and the evolution of ADHD medication consumption, and estimate the prevalence in Castile-La Mancha (Spain).

Methods: The prevalence of ADHD is estimated by calculating the Defined Daily Dose per 1000 inhabitants and day (DHD) of the total medication for ADHD (Therapeutic group N06BA) during the years 1992 to 2015. The trend its shift points and the Annual Percentages of Change (APC) using regression join point. The prevalence estimated is calculated with a model ARIMA.

Results: We estimated a prevalence of ADHD 13.22 cases per 1000 inhabitants per day for Castile-La Mancha in the population aged 5 to 19 years in 2015, the consumption total has increased a $98.93 \%$. The consumption has increased by 10.3\% APC from 1992 to 2015 with several years or join points (2000, 2009 and 2012). The prevalence estimated in 2020 is 14.11 cases per 1000 inhabitants per day.

Keywords: Hyperactivity; Psychostimulants; Incluyen; Pharmacotherapy

Received: December 03, 2016; Accepted: January 06, 2017; Published: January 16, 2017

\section{Introduction}

Attention Deficit and Hyperactivity Disorder (ADHD) is a neurodevelopment disorder with a worldwide prevalence of $5 \%$ [1]. The actual increased interest in this pathology has been promoted by the increased number of cases and the use of psychostimulants in children, being the most diagnosed behavioral disorder in this age group [1]. Recent meta-analyzes estimate an overall prevalence of 3-7\%, being in Spain $6.8 \%$, perhaps for an overdiagnosis or overtreatment [2-6]. ADHD treatment may require the use of psycho stimulants, like Metilphenidate (MPH) and Lisdexamphetamine (LDX); and not stimulants, like Atomoxetine (ATX), that are the officially drugs approved in Spain [4]. In Spain pharmacotherapy concurred with marketing of extended-release MPH formulation, about 20032004 [5]. The aim of this study was to describe trends in ADHD diagnosis, and to estimate the prevalence in Castile-La Mancha (Spain), studying the evolution of drugs consumption.

\section{Methods}

Juan-Jose Criado-Alvarez ${ }^{1,2}$, Carmen Romo-Barrientos ${ }^{1}$, Jaime González-González ${ }^{1,2}$, Juan-Carlos MonteroRubio ${ }^{1}$ and Alicia Mohedano-Moriano²

1 Regional Health Service of Castile-La Mancha (SESCAM), Talavera de la Reina, Toledo, Spain

2 Department of Medical Sciences, University of Castile-La Mancha (UCLM), Talavera de la Reina, Toledo, Spain

Corresponding author:

Juan José Criado-Álvarez

\section{$\equiv$ jjcriado@sescam.jccm.es}

Regional Health Service of Castile-La Mancha (SESCAM), 45654 San Bartolomé de las Abiertas, Talavera de la Reina, Toledo, Spain.

Tel: (+34) 925704020

Citation: Criado-Álvarez JJ, Romo Barrientos C, Gonzalez-Gonzalez J, et al. Estimating the Prevalence of Attention Deficit Hyperactivity Disorder in Castile-La Mancha, Spain (19922020). J Child Dev Disord. 2017, 3:1.

Castile-La Mancha (CLM) is the second largest region in Spain (13.6\% of the total area), with a population density of 26.7 inhabitants $/ \mathrm{km}^{2}$, being the child population a $16.4 \%$ of total. Each municipality has a wide network of pharmacies and medical center. For the period (1992-2001), the databases of the Spanish Ministry of Health has been used, which it was published previously study [6]; and for the period (2002-2015) the Health Regional Service of Castile-La Mancha (SESCAM) databases was used. Both databases offer information on the consumption of the drugs dispensed by pharmacies at the expense of the Spanish National Health 
Service; hospital consumption and private insurers are excluded. Both databases are considered an acceptable approximation of actual consumption $[5,6]$. The data were expressed in defined daily doses (DDDs) per 1000 inhabitants per day (DDD/1000 inhabitants/day), using the DDD values proposed by the World Health Organization. The formula number of DDD per 1000 inhabitants per day=Number of packages dispensed $\times$ number of doses per package $\times$ number of $\mathrm{mg}$ per dose $\times 1000$ inhabitants/ DDD in $\mathrm{mg} \times$ number of inhabitants for the year/365 days was used [7]. To avoid the influences caused by age structure of the population, the consumption for those children and adolescents $>5$ and $<18$ years also was calculated. We have selected the MPH (30 mg), ATX (80 mg) and LDX (30 mg), to N06BA04, N06BA09 and N06BA12 groups of the Anatomical Therapeutic Chemical, using the Defined Daily Doses (DDD) [5]. The total population for each year studied was obtained from the National Statistics Institute (INE). Although these drugs are the first choice in most ADHD treatment regimens patterns are also used that do not incluyen $[4,8]$. For this reason the estimates from the consumption of drugs must be considered minimum estimates of prevalence or prescription mode [8].

We used Regression models of Join point or models segmented Poisson Regression to be very effective to identify changes in trend. It is analyzing the effect over time, which behaves as an independent variable on the calculated proportions. In this analysis, the shift points (join point or inflection points) show the existence of significant changes in the trend (up or down). Each join point indicates a statistically significant change in the trend, and an Annual Percentage Rate (APC) is calculated for each of these trends, using generalized linear models assuming a Poisson distribution. Each APC is calculated with confidence interval $95 \%$ (Cl 95\%) [9].

The trend pattern and temporal prediction consumption is calculated using a model of Autoregressive Time Series (ARIMA) in total consumption of drugs for ADHD in children under 19 years, using DDD per 1000 inhabitants per day, until a future period of 5 years (2020) with $\mathrm{Cl} 95 \%$ [8].

\section{Results}

The consumption of drugs in Castile-La Mancha has been increased by $98.93 \%$, from 0.15 in 1998 to 13.22 DDD per 1000 inhabitants per day in 2015 (13,22 cases per 1000); this data can be used as an estimate of the prevalence of ADHD, for ages 5 to 19 years in Castile-La Mancha. Extrapolating to the entire population, we can see that the prevalence increases 0.03 in 1992 to 2.07 DDD per 1000 inhabitants per day in 2015. In 2015, MPH is the most consumed drug, with $89.6 \%$ of the total, as it has increased from 0.15 in 1992 (when it was the only drug available), to 11.84 DDD per 1000 inhabitants per day in 2015, an increment of $98.72 \%$. The LDX is the second most consumed drug in 2015 (8\%). The ATX is the least consumed drug, in 2015; however, consumption has increased a 61\%, from 0.12 in 2008, to 0.32 DDD per 1000 inhabitants per day in 2015.

The APC for ADHD drugs, in Castile-La Mancha, from 1992 to 2015 is $10.3 \%$ (Cl 95\%: 7.0-13.7). This increase has not been uniform, and we can see three significant join points (years 2000, 2009 and
2012) overtime. The APC of MPH, from 1992 to 2015 is $9.8 \%(\mathrm{Cl}$ 95\%: 6.5-13.3); and for ATX, from 2008-2015 is $13.1 \%$ (Cl 95\%: 2.3-24.9).

The time series model fits 2, 0, 2, which explains most of variance. In the fifth year, the temporal prediction is destabilized, with a sigmoid curve increase, for 2020 of 14.11 DDD per 1000 inhabitants per day (CI95\%: 10.18-18.05), as a prevalence estimated, which means an increase of $6.3 \%$, from 2015 to 2020 (Figure 1).

\section{Discussion}

Castile-La Mancha has increased consumption of drugs for ADHD, as in other national and international studies, with a gradual increase from 1992 to 2000 [5,8]. This increase shows a large rise in 1998, with the new MPH preparations and the appearance and marketing of ATX in 2008 [8,10]. Using DDD per 1000 inhabitants per day we estimated that prevalence in Castile-La Mancha in 2015 is 13.22 cases per 1000 , and may reach 14.11 per 1000 in 2020, for the age group 5-19 years. These data are similar to previous Spanish study, which in 2009, for MPH found a prevalence of 12 cases per 1000 [5]. The LXD has increased since its introduction in Spain, in 2014, the second most prescribed drug in Castile-La Mancha, however MPH continue being the drug of choice, with $90 \%$ of consumption [10-12].

The prevalence of ADHD in Spain is estimated at $6.8 \%$, being similar to other European countries, with $5.5 \%[2,13]$. In our study, we have obtained 2.07 cases per 1000 for the total population, lower than international studies, but the pattern of consumption tending to rise, is increasingly similar to Nordic countries, with 2.18 cases per 1000 [12,14].

Throughout Castile-La Mancha, an average increase is observed, with an annual consumption of $10.3 \%$; this increase does not seem attributable to the increased incidence of the disease, but rather different variables, such as active case finding, improved diagnosis and care of patients, treatment with drugs of less severe cases, who did not receive treatment before, and an improvement in child health. The increased use of drugs for ADHD, with an over diagnosis and overtreatment, may be promoted by, increased awareness of the general and medical population, marketing strategy, the emergence of new drugs, with fewer side effects, and by the easy administration [8,11-14].

The availability of data consumption of drugs, in the public system, from 1992-2015, is exhaustive, to determine the prevalence of $A D H D$, and it depends on three variables: the treatment is suitably performed (this occurs in $80 \%$ of cases, for the therapeutic efficacy of MPH, which is replaced by ATX and LDX, when the first is not effective [15], the compliance with therapeutic doses (because, some drugs are not consumed, for lack of adherence or adverse effects), and finally, that ill people visits public health services [7]. Drug therapy has proven to be cost-efficient in the short term, but it should not be used in mild cases, and as the only therapeutic solution, proposing a multimodal treatment [15]. Make an effort to inform parents, teachers, doctors, psychologists and administration about ADHD. 


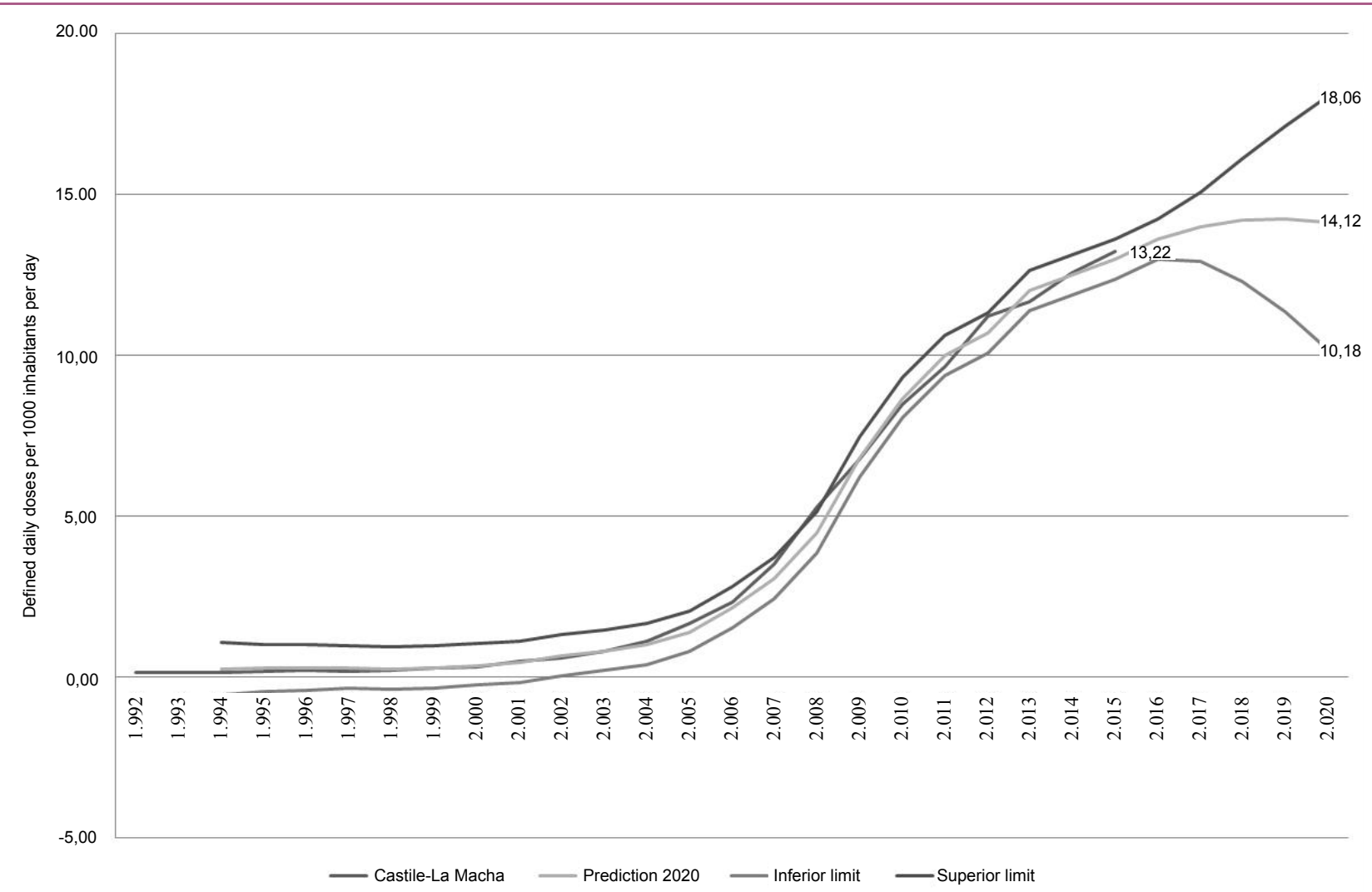

Figure 1 Increased percentage level of drugs consumption in Castile-La Mancha.

\section{Conclusion}

The consumption of drugs estimated the distribution of ADHD in Castile-La Mancha. The changes in the use of stimulants are a warning of a possible over diagnosis or a marketing strategy, and explain the possible growth in consumption of these drugs. 


\section{References}

1 Thapar A, Cooper M (2015) Attention deficit hyperactivity disorder. Lancet.

2 Polanczyk G, de Lima MS, Horta BL, Biederman J, Rohde LA (2007) The worldwide prevalence of ADHD: a systematic review and metaregression analysis. Am J Psychiatry 164: 942-948.

3 Connor DF (2002) Preschool attention deficit hyperactivity disorder: a review of prevalence, diagnosis, neurobiology and stimulant treatment. J Dev Behav Pediatr 23: S1-S9.

4 Soutullo C, Álvarez-Gómez MJ (2013) Bases para la elección de tratamiento farmacológico en el trastorno por déficit de atención/ hiperactividad. Rev Neurol 56: S119-S129.

5 Treceño C, Martín Arias LH, Sáinz M, Salado I, García Ortega P, et al. (2012) Trends in the consumption of attention deficit hyperactivity disorder medications in Castilla y León (Spain): changes in the consumption pattern following the introduction of extended release methylphenidate. Pharmacoepidemiol Drug Saf 21: 435-441.

6 Criado-Álvarez JJ, González González J, Romo Barrientos C, Mohedano Moriano A, Montero Rubio JC, et al. (2016) Variability and trends in drug consumption for Attention Deficit Disorder and Hyperactivity in Castilla-La Mancha. España: Neurología.

7 Sartor F, Walckiers D (1995) Estimate of disease prevalence using drug consumption data. Am J Epidemiol 141: 782-787.
8 Zito JM, Safer DJ, dosReis S, Gardner JF, Boles M, et al. (2000) Trends in the prescribing of psychotropic medications to preschoolers. JAMA 283: 1025-1030

9 https://surveillance.cancer.gov/joinpoint/

10 Olfson M, Gameroff MJ, Marcus SC, Jensen PS (2003) National trends in the treatment of attention deficit hyperactivity disorder. Am J Psychiatry 160: 1071-1077

11 Boland F, Galvin R, Reulbach U, Motterlini N, Kelly D, et al. (2015) Psychostimulant prescribing trends in a paediatric population in Ireland: a national cohort study. BMC Pediatrics 15: e118

12 Ponizovsky AM, Marom E, Fitoussi I (2014) Trends in attention deficit hyperactivity disorder drugs consumption, Israel, 2005-2012. Pharmacoepidemiol Drug Saf 23: 534-538

13 Catalá-López F, Peiró S, Ridao M, Sanfélix-Gimeno G, Gènova-Maleras $R$ (2012) Prevalence of attention deficit hyperactivity disorder among children and adolescents in Spain: a systematic review and metaanalysis of epidemiological studies. BMC Psychiatry 12: e168

14 Zoëga H, Furu K, Halldórsson M, Thomsen PH, Sourander A, et al. (2011) Use of ADHD drugs in the Nordic countries: a populationbased comparison study. Acta Psychiatr Scand 123: 360-367

15 Catalá-López F, Hutton B, Núñez-Beltrán A, Mayhew AD, Page MJ, et al. (2015) The pharmacological and non-pharmacological treatment of attention deficit hyperactivity disorder in children and adolescents: protocol for a systematic review and network metaanalysis of randomized controlled trials. Syst Rev 4: e19. 